\title{
Influence of Peer Pressure as a Determinant of Premarital Sexual Behaviour among Senior Secondary School Students in Kaduna State, Nigeria
}

\section{O L BADAKI ${ }^{*}$ AND M F ADEOLA ${ }^{2}$}

Department of Science Education (Human Kinetics and Health Education Unit) Federal University Dutsin-Ma, Katsina State, Nigeria

Department of Physical and Health Education Ahmadu Bello University, Zaria, Kaduna State, Nigeria

\section{*Email: badakiolusegun15@gmail.com}

Received: February 18, 2017| Revised: March 02, 2017| Accepted: March 13, 2017

Published online: April 10, 2017

The Author(s) 2017. This article is published with open access at www .chitkara.edu. in/Publications

\begin{abstract}
This study investigated peer pressure influence on premarital sexual behaviour of senior secondary school students in Kaduna State, Nigeria. The population for the study comprised students in public senior secondary schools in the twenty-three Local Government Areas of Kaduna State. Simple random sampling was used to select Kaduna North senatorial zones from the three existing zones in Kaduna State. Nine schools from thirty-two senior secondary schools were randomly selected. The population of senior secondary schools in Kaduna North zone was 5,730 in 2010/2011.50\% (2,865) of the population was used as sample size. A total number of 1,655 males and 1,210 female students were used. In each of the nine (9) schools, 319 copies of questionnaire were administered to the Students using simple random sampling technique. The data collected were statistically analyzed using descriptive statistics of mean, and standard deviation. The hypothesis was tested using one sample Z-test at 0.05 level of significance. It was found that, there is significant influence of peer pressure on premarital sexual behaviour among senior secondary school students in Kaduna State, Nigeria. It was recommended, that Kaduna State Ministry of Education to intensify awareness programme on premarital sexual behaviour through workshops or seminars for the students on how to deal with peer pressure, and other social pressures that may lead to sexual intercourse.
\end{abstract}

Keywords: Influence, Peer pressure, Determinants, Premarital, Sexual Behaviour
Journal of Multidisciplinary Research in Healthcare Vol-3, No-2, April 2017 pp. 151-159 
Badaki, OL Adeola, MF

\section{INTRODUCTION}

Premarital sexual behaviour commonly found among the adolescents was linked to peer's influence primarily through relationships, communications, interactions, connections and control within peer groups. Social interactions with peers often expose adolescent students to the cultural norms and values that are more likely to facilitate premarital sexual behaviour [15].

Furthered that peer influence is stronger in males than females because males usually initiate love or sex and also appear to be freer than girls to live on their own and, most likely, to experiment with sex. Almost half of the adolescents in a survey in Mongolia claimed to have received their sexuality information from friends [15]. [5] was of the view that, the measure of peer sexual experience that were common among the adolescents indicated a strong peer influence such that those whose peers were thought to have had sexual experience have themselves had premarital sex than those whose peers have not had such an experience.

According to [7], there has been a typically shift of adolescent students in their sphere of influence from parents to their peers. His study further showed that peers played an important role in influencing the lives of students concerning decisions on premarital sexual behaviour. The effects in peer sexual behaviour increase the likelihood of students engaging in premarital sexual behaviour because, peer role is known to change personality, attitude and behaviour of students [11]. Evidence shows that in all societies, peer sexual behaviour is a model for individual behaviour and this is certainly true in matters of sexuality among adolescents. Sometimes peer pressure upon a person can lead him or her to engage in premarital sexual behaviour through associated behaviour such as drinking of alcohol and visiting commercial sex workers [12]. [10] discovered in their study that, adolescent students who sought information from their peers were sexually experienced compared to those who sought information from parents, teachers and other sources such as media, religious centers, and adults, etc. They further observed that most friends in the social context of Nigeria students would likely respect the final choice of their peers to engage in premarital sexual behaviour than that of their parents. In a study conducted by [6]; [13] among adolescents in a slum setting and the surrounding rural areas in India, discovered that the level of self-confidence and peer interaction were significantly associated with reports of experiences of romantic and premarital sex [17] in their study found that adolescents who reported having been influenced by friends to engage in premarital sexual behaviour were low in percentage $(30 \%)$. This finding seems to contradict the view that adolescents are under great pressure from 
their friends or peers to engage in premarital sexual behaviour as expressed in various studies. It was observed that, for adolescent students in most developing countries, information on sexual matters comes either from their peers, who may be equally uninformed or incorrectly informed and are likely to be relatively inexperienced, or from the media, which tends to represent sexual and gender stereotypes and extremes [16]. This background thus led to research on the influence of peer pressure as a determinant of premarital sexual behaviour among senior secondary school students in Kaduna State, Nigeria
Influence of Peer Pressure as a

Determinant of Premarital Sexual Behaviour among Senior Secondary School Students in Kaduna State,

Nigeria

\section{STATEMENT OF THE PROBLEM}

Nigeria has experienced profound social and moral changes associated with economic reforms and attitudes towards premarital sex. And this may have led to growing increase in numbers of peer pressure leading to premarital sexual behaviour which are often reported among students in secondary school students in Nigeria [1]. Likewise, studies on reproductive health behaviour of students in Nigeria indicates that many secondary school adolescents usually initiate sexual intercourse at an early age and engage in high risk premarital sexual behaviour [10]. However, since the determinants of students' premarital sexual behaviour differs from continent to continent, country to country; between culture and also can be influenced or affected by many factors; hence the need to carry out a research work on a wider scope and coverage that will identify the major factors influencing or determining premarital sexual behaviour among secondary school students is important. This has therefore prompted the researcher to investigate the influence of peer pressure as a determinant of premarital sexual behaviour among senior secondary school students in Kaduna State, Nigeria.

\section{METHODOLOGY}

The population for this study comprise all male and female students from the 234 senior secondary schools in the twenty-three local government in Kaduna State, Nigeria. The schools were group into the existing three senatorial zones which were; Kaduna South, Kaduna North and Kaduna Central. A simple random sampling technique of fish bowl method of dip and pick was used to select Kaduna North Senatorial District for this study. Kaduna North Senatorial District comprised Zaria, Sabon Gari, Kudan, Soba, Markarfi, Ikara, Kubau and Lere. Nine schools were randomly selected from the thirty-two public senior secondary schools in Kaduna North Senatorial District. The population of nine selected public senior secondary schools in Kaduna North senatorial 
Badaki, OL Adeola, MF district was 5,730 in 2010/2011as provided by Kaduna State Ministry of Education, Statistics Department [4]. A sample size of 2,865 students from nine selected senior secondary schools in Kaduna North Senatorial District was randomly selected which formed $50 \%$ of the study population. A total number of 1,655 males and 1,210 female students were used for the study. In each of the nine (9) schools, 319 copies of questionnaire were administered to each of the senior secondary school students in SSS1, SSSII and SSSIII using simple random sampling technique. According to [2]; [14] explain random sampling as process of selecting a sample in such a way that all the individuals in the defined population have an equal and independent chance of being selected as a sample. It is most suitable for homogeneous population [8]. The instrument used to collect information was a researcher-structured questions of a five point - Likert rating Scale format. The instrument was validated and tested for reliability. A reliability correlation coefficient of 0.907 was obtained. The instrument was administered by the researcher and five trained research assistants. The data was analyzed using descriptive statistics of mean, standard deviation and $\mathrm{Z}-$ Score at 0.05 alpha level.

Objective of the Study: To examine peer pressure as a determinant of premarital sexual behaviour among senior secondary school students in Kaduna State, Nigeria.

Specific Objective: To determine the influence of peer pressure on premarital sexual behaviour of senior secondary school students in Kaduna State, Nigeria.

Research Question: Does peer pressure have any influence on premarital sexual behaviour among senior secondary school students in Kaduna State, Nigeria?

Table1 revealed that $644(22.5 \%)$ of class of students were from Senior Secondary School) S.S.S. I, 1025 (35.8\%) were in S.S.S II and 1,195(41.7\%) were in S.S.S.III.

On gender, Table1 indicated that 1,655 (57.8\%) were male while 1,210 $(42.2 \%)$ were female. This classification, though not equitably distributed but shows that the opinions of male and female respondents were represented in the study. This helped to take off the gender bias aspect of the study and since all decisions were based on weighted Means scores which were devoid of numbers.

The parents level of education as revealed in Table 1 shows that 368 $(12.8 \%)$ of the respondent's parents had no formal education while 1,145 $(40 \%)$ had primary school certificates. Respondents whose parents had secondary school certificate were $549(19.2 \%)$ and those with parents who had tertiary education certificate were 803 (28.0\%). This information shows that, majority of the respondents parents had low level of education. 
Table 1: Demographic Profile of Respondent.

\begin{tabular}{lll}
\hline Class & Frequency & Percentage \\
\hline SSS I & 644 & 22.5 \\
SSS II & 1,025 & 35.8 \\
SSS III & 1,196 & 41.7 \\
Total & $\mathbf{2 , 8 6 5}$ & $\mathbf{1 0 0 . 0}$ \\
\hline Gender & Frequency & Percentage \\
\hline Male & 1,655 & 57.8 \\
Female & 1,210 & 42.2 \\
Total & $\mathbf{2 , 8 6 5}$ & $\mathbf{1 0 0 . 0}$ \\
\hline Parent Education & Frequency & Percentage \\
\hline Not educated & 368 & 12.8 \\
Primary & 1,145 & 40.0 \\
Secondary & 549 & 19.2 \\
Tertiary & 803 & 28.0 \\
Total & $\mathbf{2 , 8 6 5}$ & $\mathbf{1 0 0 . 0}$ \\
\hline Parent Marital Status & Frequency & Percentage \\
\hline Single & 92 & 3.2 \\
Married & 2,547 & 88.9 \\
Divorced & 117 & 4.1 \\
Widowed/widower & 74 & 2.6 \\
Separated & 35 & 1.2 \\
Total & $\mathbf{2 , 8 6 5}$ & $\mathbf{1 0 0 . 0}$ \\
\hline Age & Frequency & Percentage \\
\hline 11- 13 yrs & 482 & 16.8 \\
14 - 16 yrs & 792 & 27.6 \\
Above 16 yrs & 1,591 & 55.5 \\
Total & $\mathbf{2 , 8 6 5}$ & $\mathbf{1 0 0 . 0}$ \\
\hline & &
\end{tabular}

Influence of Peer Pressure as a Determinant of Premarital Sexual Behaviour among Senior Secondary School Students in Kaduna State, Nigeria 
Badaki, OL Adeola, MF classifications clearly showed that the majority of the respondents were from married parents but had representations from single, divorced and separated parents as well.

Table1 also showed that $482(16.8 \%)$ of the respondents age were between $11-13$ years. Those who were between $14-16$ years were $792(27.6 \%)$ while $1,591(55.6 \%)$ were above 16 years. The variability was in favour of the older age respondents which probably account for the selection of the senior classes in the secondary schools involved in this study.

The score in Table 2 revealed that respondents' pressure by their peers was a major determinant of premarital sexual behaviour among senior secondary school students in Kaduna State as indicated in the aggregate Mean score of 4.72 which was above the bench mark of 3.5 of Likert Scale rating. This implied that most respondents involved in the study were in agreement with variable in items first to sixth in the table. This means that pressures by peers, that have regular sexual partners, students who seek sexual information from friends, socializing with sexually experienced peers/friends were major determinants of premarital sexual behaviour among senior secondary school students in Kaduna State.

Table 2: Mean scores and standard deviation of peer pressure as a determinant of premarital sexual behaviour.

\begin{tabular}{lll}
\hline Items & Mean & $\begin{array}{c}\text { Standard } \\
\text { Deviation }\end{array}$ \\
\hline $\begin{array}{l}\text { 1. The pressures I receive from my peers make me } \\
\text { engage in premarital sexual behaviour. }\end{array}$ & 4.72 & 0.448 \\
$\begin{array}{l}\text { 2. I engage in premarital sexual behaviour because I } \\
\text { have peers that have regular sexual partners. }\end{array}$ & 4.56 & 0.596 \\
$\begin{array}{l}\text { 3. Students who seek sexual information from } \\
\text { friends engage mere in premarital sexual }\end{array}$ & 4.39 & 0.675 \\
$\quad \begin{array}{l}\text { behaviour } \\
\text { 4. Socializing with sexually experienced peers/ } \\
\text { friends make me engage in premarital sexual } \\
\text { behaviour }\end{array}$ & 3.76 & 0.824 \\
$\begin{array}{l}\text { 5. My peers encourage me to engage in premarital } \\
\text { sexual behaviour }\end{array}$ & 4.28 & 0.508 \\
$\begin{array}{l}\text { 6. My friends/peers reject me for not engaging in } \\
\text { premarital sexual behavior }\end{array}$ & 3.83 & 0.871 \\
\begin{tabular}{l} 
Aggregate Mean score \\
\hline
\end{tabular} & $\mathbf{4 . 2 6}$ & $\mathbf{0 . 3 1 4}$ \\
\hline
\end{tabular}


Table 3: One sample Z-test on peer pressure as a determinant of premarital sexual behaviour among senior secondary school students in Kaduna State, Nigeria.

\begin{tabular}{llllllll}
\hline Variables & N & Mean & Std. Dev. & Std. Error & Z -value & DF & Sig. \\
\hline Peer pressure & 2,865 & 4.2556 & 0.31365 & 0.00586 & 7.742 & 2,864 & 0.000 \\
Fixed means & 2,865 & 3.500 & 0.0000 & 0.000 & & & \\
\hline
\end{tabular}

(Z- critical $=1.96, \mathrm{P}=0.05)$

\section{TESTING HYPOTHESIS}

Peer pressure does not significantly influence premarital sexual behaviour among senior secondary school students in Kaduna State, Nigeria.

Table 3 revealed that respondents agreed that peer pressure could be a significant determinant of premarital sexual behaviour of senior secondary school students in Kaduna State. This was indicated with a Z-value of 7.742 compared to the critical value of 1.96 and an observed significant level of 0.000 $(\mathrm{P}<0.05)$. This means that respondents were of the opinion that peer pressure was a major determinant of premarital sexual behavior among students in senior secondary schools in Kaduna State. Therefore, the null hypothesis that peer pressure does not significantly influence premarital sexual behaviour among senior secondary school students in Kaduna State was rejected.

\section{DISCUSSIONS}

The finding of this study indicated that students seek information from their peers on sexual issues. Therefore, the finding tends to be consistent with [3] and [6] who submitted that students' premarital sexual behaviour was linked to peer influence, primarily through relationships, communication, interaction connections and control within peer groups. They noted that peers often provide important models of attitude and behaviour for adolescent students and that student whose peers have had premarital sexual experience tend to engage in the same behaviours.

In line with this finding [11], [12] observed that the effects of peer sexual behaviour increase the likelihood of students engaging in premarital sexual behaviour because peer role is known to change personality, attitude and behaviour of students. They pointed out that, peer behaviour is a model for individual behaviour and this is certainly true in matters of sexuality among adolescents. Sometimes peer pressure upon adolescent students can lead him or her to engage in premarital sexual behaviour through associated behaviour such as drinking of
Influence of Peer Pressure as a

Determinant of Premarital Sexual Behaviour among Senior Secondary School Students in Kaduna State, Nigeria 
Badaki, OL Adeola, MF

alcohol and visiting commercial sex workers [12]. In a study [12] showed that students who socialized with sexually experienced peer were nearly seven times more likely to have sex than those whose peers were not sexuality experienced.

Reference [10], [9] opined that adolescent students who sought information from their peers were sexually experienced compared to those who sought information from parents, teachers and other sources such as media, religious centers, and adults, etc. They further observed that most friends in the social context of Nigerian students would likely respect the final choice of their peer to engage in premarital sexual behaviour than that of their parents. Therefore, the impact of peer group plays a significant role in influencing views, attitudes and sexual behaviour of adolescent students. Adolescent students relied more on their peers on matters relating to sexual behaviour, thus exposing them to an unimaginable pressure to engage in premarital sexual behaviour.

\section{CONCLUSION}

The outcome of the study shows that, peer pressure as one of the major factors that influence premarital sexual behaviour among senior secondary school students in Kaduna State was highly significant. In other word, respondents were able to establish strong link between peer pressure and premarital sexual behaviour.

\section{RECOMMENDATIONS}

(i) There is the need for the Kaduna State Ministry of Education to intensify awareness programme on premarital sexual behavior through workshops or seminars for the students on how to deal with peer pressure, and other social pressures that may lead to sexual intercourse.

(ii) There is the need for students to be adequately taught Family and Sexuality Education where they will learn how to select friends, events, places and experiences that are safe in order to avoid being in tricky situations that may lead to sexual intercourse.

\section{REFERENCES}

[1] A.M Fatusi, \& R.W. Blum (2008). Predicators of early sexual initiation among a nationally representative sample of Nigerian adolescents. BMC Public Health: 8, 136.

[2] B.G Nworgu (1991). Education Research; Basic Issues and Methodology: Ibadan: Wisdom publishing Ltd. 45.

[3] K. Hallman (2004). Socio-economic Disadvantage and unsafe sexual Behaviours among young women and men in South Africa. The population Council, Inc. 190. 
[4] Kaduna State Ministry of Education, Statistics Department 2010/2011. Nigeria

[5] L.P Wong. Qualitative Inquiry into contraceptive use among Multi ethnic young women: implications for education and future research. Plos ONE 7(12). (2012).

[6] M. Alexander, et al (2007). Correlates of Premarital relationships among University Youth in Pune District, Maharashtra, India, International Family Planning Perspectives 23(4).

[7] M.F. Adeola (2014). The determinants of premarital sexual behaviour of Nigerian Senior Secondary School students. Dissertation in partial fulfillment of award of Ph.D in Health Education. Ahmadu Bello University, Zaria, Nigeria (Unpublished). 36

[8] M.O Araoye (2004). Research Methodology with statistics for health and social sciences. NATHADEX Publishers, Odo-Okun Sawmill, Ilorin. 115-121.

[9] O.E Amoran, M.O Onadeko, \& J.D Adeniyi (2005). Parental Influence on adolescent sexual initiation practices in Ibadan, Nigeria, International Quarterly Journal of Community Health Education 23 (1) 73-81.

[10] P.T Okonkwo, A.O Fatusi,., and A.I Ilika (2005). Perception of peers' behaviour regarding sexual behaviour decision making among female undergraduate in Anambra State, Nigeria: African, Health Sciences 5(2), 107-113.

[11] R Adhikari (2013). Premarital sex: attitude and behavior among college students. Lambert academic publishing.

[12] R. Adhikari (2009). Premarital sexual behaviour among college students of Kathmandu, Nepal: BMC public Health 9, 241.

[13] R. Sujay (2009). Premarital Sexual behaviour among unmarried college students of Gujarat, India. Health and population innovation fellowship programme working paper, 9 .

[14] R.Bello, \& O.O.S Ajayi (2000). Research methods and statistical analysis: Ilorin Haytee Press Publishing Comp. Ltd.

[15] S. Algaa (2000). The Factors Affecting In-School Adolescents in Mongolia. Unpublished M.A Thesis. Mahidol University.

[16] T. Omotere (2012). The influence of peer group pressure on sexual Behaviour of secondary school students in Ijebu-ode local government Area of Ogun state Published online by Ego Booster Books. www.omolere.tk.

[17] T. Wang'eri, \& F. H Otanga (2013). Family, peer and protective factors related to sex behavior among urban adolescents in secondary schools in mombase, county, coast province, Kenya. International journal of IEducation and research. (1) 5.
Influence of Peer

Pressure as a

Determinant of

Premarital Sexual

Behaviour among

Senior Secondary

School Students

in Kaduna State,

Nigeria 